\title{
Introduction of a Strategic Board Game that is Aimed at Educating Children About Sustainable Development Goals of United Nations
}

\author{
Sirin Guney Ozenc
}

Turkey

\begin{abstract}
The paper I want to share at this Education Conference is not the result of a research, but it is a product of a 26-year long education career. With all my observations during these 26 years, I found that especially high school students' global awareness is low and developing a better awareness has become the forefront of my education phylosophy, so I create a syllabus and developed a strategic board game. I am a generation $\mathrm{X}$ teacher who tries to raise the generation $\mathrm{Z}$ kids and construct an education system for the Generation Alpha. On the other hand,Y-generation, my young colleagues that I am working with are also very different from me, but still,we are sharing the same planet that needs our immediate care and awareness. The main goal of this syllabus is teaching the UN Sustainable Development Goals, so that they can internalize the goals to take actions. This paper contains the basic chapter explanations of the curriculum and the rulee of the strategic board game ECOTOPIA. In short, this curriculum and strategic board game is the product my educational experience and I would like to get support/opinion from my colleagues by presenting them in this conference. The philosophy of the curriculum is rising Global Awareness meanwhile understanding the sustainable development goals (SDG). On the other hand, the game Ecotopia is just covering some development goals. The game focused on renewable energy sources and pollution. When a student starts playing the game he/she has learned the renewable energy sources, pollution sources and etc but by the end of the game he/she would have a solid idea about how other countries affect your nature, how do states make decisions to change their investments nature friendly like electric cars, how unexpeced disasters like earthquake effec the country,how global warming is increasing aoutomatically and as World citizenship you nedd to take some actions to reduce it. Participants in the game need to develop various strategies regarding ecological conditions, sustainable energy sources, as well as attitudes towards air, water, and soil pollution. The goal of every player is to create a healthy and sustainable state.
\end{abstract}

Keywords: High School, Curriculum, Integrated Course, Sustainability, Development, Goal, Macroeconomy, Generations (X, Y Z), Globe, Awareness, Strategic Board Game, Ecotopia, World Citizenship, renewable energy sources, investment

\section{Introduction}

Generation X teachers' (born between 1965 and 1981) philosophy of life is working and producing. They went through the entire period of technological evolution and the rise and development of the media. They all learned how to use a computer when they are teaching 
classes. Some times those educators ask help from their students. In spite of having adapted to cellphones, internet, computer and smart technologies,they are less dependent on the technology.

On the other hand their young colleagues, generation $\mathrm{Y}$ are known as digital natives, millennials are those born between 1982 and 1994. Technology is part of their everyday lives. Unlike their parents or Generation X, digital natives are not satisfied with the world around them and are ambitious and want to achieve their goals.So as being elder educators we are also giving our hand to generation $\mathrm{Y}$ for constructing the new model of education.

Today's students; aged between eight and 23 years old, Generation Z or the postmillennial generation, also labelled as centennials, for having been born into the world at the turn of the century - the oldest were born in 1995 and the youngest in 2010 - they arrived with a tablet and a smartphone under their arms.

They like to get everything they want immediately, a fact fostered by the digital world in which they are immersed, and their lifestyle is also influenced by youtubers.

They multi-task, but their attention span is limited. They are independent and demanding consumers and will have jobs that do not exist in today's world.

Generation $\mathrm{Z}$ who are ready for fast learning and access to information immediately need an education that has many basic knowledge from different fields. Their courses should be different from the usual ones. An attractive course content and material like a strategic game lead them to take action. This generation can reach the knowledge easily and do not need to summarize all details that generation $\mathrm{X}$ did.

So all for these reasons, in order to take attention of generation Z students and support of generation $Y$ teachers, a strategic board game that adressess the main goal of course can be very helpful.

\section{Discussion}

The game is called as ECOTOPIA, and based on UN Sustainable Development Goals. UN Educational, Scientific and Cultural Organization's Education for SDG Learning Objectives book (Rickemann, 2017) says UNESCO has been promoting Education for Sustainable Development (ESD) since 1992. It led the UN Decade for ESD from 2005 to 2014 is now

spearheading its follow-up, The Global Action Programme (GAP) on ESD.

Even though the importance of UN Sutainable Development Goals has been known for a long time, with the epidemic, the new normal life proved the importance those goals. As a result in these troubled times, we all need to know how to take care of the Earth and life. The game is focused on some SDG (numbers; 2,3,4,6,7,13,14,15,17) and trying to teach them with the help of main environment concept. 


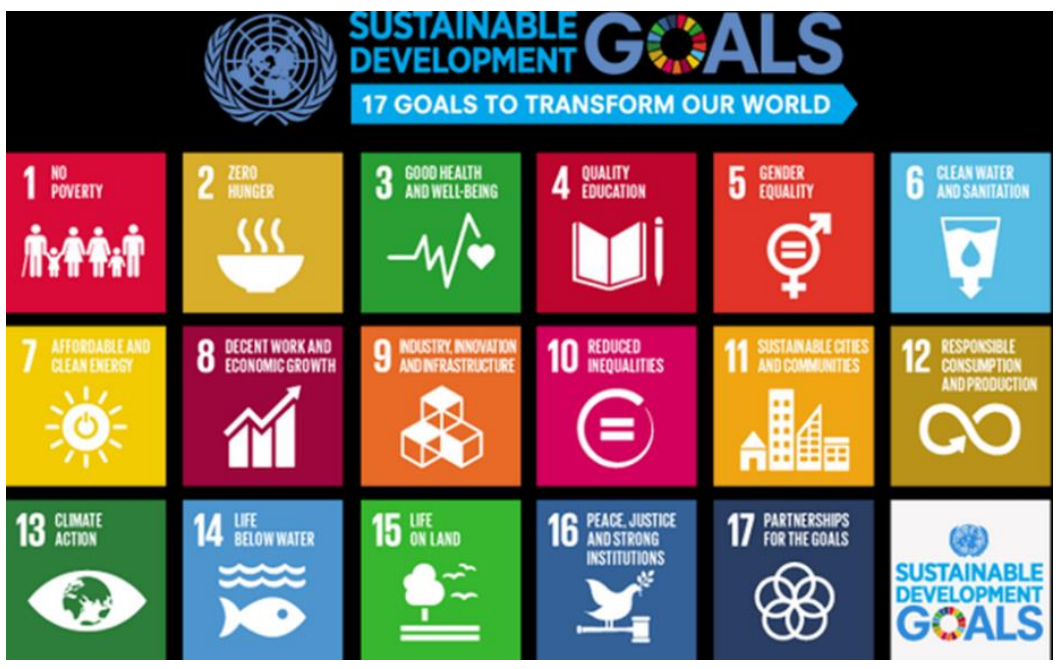

When I checked the literature about teaching SDG by environment education concept and pollution levels of countries, I have seen that "Environmental Education and Sustainable Development: A Further Appraisal” L. Sauvé, Université du Québec à Montréal, Canada wrote an article to pursue critical reflection with regard to the links between Environment Education (EE) and sustainable development. His typology of conceptions of the environment "A phenomenographic study of discourses and practices in EE" (Sauvé, 1992) identifies six paradigmatic conceptions of the environment. The influence of these different conceptions can be observed in the pedagogical approaches and strategies suggested by different authors or adopted by educators (Sauvé, 1994): environment as nature,environment as a resource,environment as a problem, Environment as a place to live, Environment as the biosphere, Environment as a community project.

Basically the Ecotopia game has all typology of conceptions written above.

Also since Ecotopia is a strategic board game we might need to think about the strategies of countries on this issue. The game would like to make students desicion maker and risk taker to reduce pollution. The book "As a Road Map for Achieving the SDG" (Tasyum, 2020) should be mentioned.

The book offers how education policy needs to provide a roadmap for giving citizens the thinking tools they need to make sence of the SDG as autonomous rational mature citizens in becoming. The writer says the education policy needs to include Intended learning Outcomes that will allow the road map to direct citizens to know how to associate with different SDGs, and how they can work with institutions of society where universities bridge between them. In that perspective Ecotopia game is a kind of learning outcome practice tool for high school and middle school students

\section{The content of the Global Awareness Curriculum}

Geographical features of the Earth, basic properties of the continents and their main natural resources, effects of these natural resources on life, clean and renewable energy sources, macroeconomics terms, meaning of being entrepreneurship, understanding the importance of being World Citizenship, future and developing technologies, society 5.0 and of course, as the 
main umbrella, the United Nations Sustainable Development Goals. As you can all see the curriculum is the integration of many important fields. As I mentioned previously the course and a the game try to get attention of generation $\mathrm{Z}$ who are ready for fast learning and a ccess to information immediately.

(Dale_and Newman ,2005) ,The book named "Educating Citizens for Global Awareness" describes the importance of Global Awareness. The great wave of globalization is underlined. This concept is of course part of the curriculum I wrote above. So for result of research when we checked the literature, there are plenty of course curriculums and applications about Global Awareness, so I do not continue on that side,on this paper, I would like to introduce the strategic board game Ecotopia in detail.

When I made literature search for" teaching SDG with a game", again there are lots of creative tools/games that were developed by educators. Catch is one of them. Catch: A New, SDGAligned Learning for Transformative Change Game is developed by Harold Glasser , Alan Rea, and Isaac Green. Their article published at June 2018, discusses the fun and engaging game that embodies a promising new pedagogical approach for helping to address three common learning failures that stymy efforts to create transformative change. Aligned with UN Sustainable Development Goals and Sustainability Core Competencies, the Catch game is a resource for teaching, learning, and researching about the management of common pool, renewable natural resources (fisheries, pastures, forests, irrigation systems, etc.). Importantly, it also addresses the relationships between human well-being, resource management, learning, planning, and decision-making more broadly.

ECOTOPIA is a board game based on ideas of sustainability and continuous development. Participants in the game need to develop various strategies regarding ecological conditions, sustainable energy sources, as well as attitudes towards air, water, and soil pollution. The goal of every player is to create a healthy and sustainable state. Drawing on the insight that the environment is a common resource to all, the game is constructed in such a way that collaborative strategies, rather than destructive ones, prove successful for each participant. Ecotopia functions as a fun model through which players can understand what type of approaches will be useful in the real world and the dire need for cooperative strategies to overcome the calamities of the $21^{\text {st }}$ Century.

The main idea of the game is making some SDG attractive, so there is no winner. When at least one country reaches zero pollution the game ends, while playing the game students should make constructive decisions for the common goal.

He/she must know how to be collaborative country to achieve goals. The other participants who have not reached zero pollution level are not losing, because they are always reducing the pollution, so their pollution level is lower when the game ends.

The Instruction and Rulee of ECOTOPIA is given below

\section{Ecotopia}

ECOTOPIA is a game designed to educate children over 8 years of age

It is about SUSTAINABILITY and consequences of human activities to our planet's ecology. The number of players: $\min 2-\max 6$. 
OBJECT... The object of the game is to become the first country to achieve zero pollution level in 3 areas: AIR, WATER, EARTH.

$\mathrm{CO}_{2}$ Level which causes Global warming, is a common pollution parameter that applies to all players. If Global warming goes over the maximum limit, everybody loses.

EQUIPMENT... The equipment consists of 1 board, 2 dice, 6 tokens for each country,120 red beads to represent air pollution, 120 blue beads to represent air pollution and 120 brown beads to represent soil pollution. , 1 indicator token for global warming, 20 disaster cards and 28 investment cards to reduce pollution. Money: 2020 ש (Twenty ecohin), 20 ten ecoshin,40 five ecoshin,50 two ecoshin and 50 one ecoshin

DISASTER CARDS... Those cards are going to be on the board on their allotted place. They are disasters like earthquake, hurricane, epidemic disease, flood...Each card has a cost that the country should pay to union.

COUNTRIES... There are six different countries each represented with a specific color and token. The names are: Gardenburg, Nesrina Land, Aiya Republic, High United South Cost, Semretopia, Envy Island State. On the cards of each country you can see the pollution levels of air, water, and soil. The levels are different but the total of those different type of pollution levels are same.

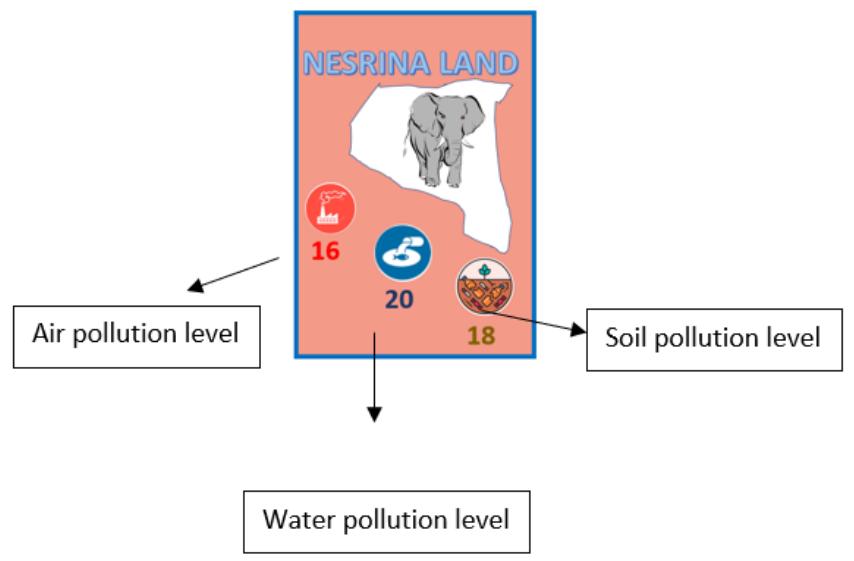

PREPARATION... Place the board on a table and put the Disaster Cards face down on their allotted spaces on the board. Investment cards are placed on the edge of the board of that same identical space.

Each player chooses one token to represent him/her while traveling around the board. Each player selects a country and at the beginning of the play he /she will take the exact number of beads from the Union to see his/her pollution level. (Ex: Nesrina Land player will take 16 red bead,20 blue bead,18 brown bead as written on card.)

Each player is given $ש 50$ Ecoshin divided as follows: 1 each of ש20's, ש 10's and 2 \$5's and 3 ש2's; 4 each of $\$ 1$ 's.

All remaining money and other equipment go to the Union of Countries Bank (UCB) ...

Select a player as President of the Union of Countries. A President who plays in the game must keep his/her country funds and pollution beads separate from those of the Union. 
THE UNION ... Besides the money, the UNION holds the rest of the pollution beads and global warming responsibility.

START... All participants roll both dice. Player with the highest dice score is first to choose his/her country and start the game. Other players follow in a clockwise manner.

POLLUTION LEVELS... Each country (player) suffers from pollution in 3 different areas (air, water, earth). After a player plays his turn; each pollution parameter of that Player's country goes up by 1 point but reduced by the benefits coming from Investments.

NAMES OF THE COUNTRIES: Gardenburg, Nesrina Land, Aiya Republic, Envy Island State, Semretopia, High United South Cost

INVESTMENTS... Investments made by countries help reduce the pollution of that country as much as the numbers indicated on the cards. Investments also provide financial income. After each move, the player can decide to buy the investment he/she is at. If investment position has been previously purchased by another player, there is no penalty or cost that needs to be paid between players. The owner of that investment might sell the investment to the other player who comes

INVESTMENT CARDS... These cards are all about sustainable development goals but basically focused on goal numbers 2,3,4,6,7,13,14,15,17.

The investment cards are ; electric car, reforestation, wind energy, solar energy farms, recycling incentives, organic farming, waste water treatment, energy efficiency incentives, research and development and environmental education

\section{POLLUTION LEVELS OF COUNTRIES...}

Pollution levels at the beginning of the game are below:

\begin{tabular}{|l|l|l|l|l|l|l|}
\hline $\begin{array}{l}\text { Pollution } \\
\text { Type }\end{array}$ & GARDENBURG & $\begin{array}{l}\text { NESRINA } \\
\text { LAND }\end{array}$ & $\begin{array}{l}\text { AIYA } \\
\text { REPUBLIC }\end{array}$ & $\begin{array}{l}\text { HIGH } \\
\text { UNITED } \\
\text { S. COST }\end{array}$ & SEMRETOPIA & $\begin{array}{l}\text { ENVY } \\
\text { ISLAND } \\
\text { STATE }\end{array}$ \\
\hline AIR & 20 & 16 & 18 & 20 & 17 & 17 \\
\hline Water & 18 & 20 & 16 & 17 & 20 & 17 \\
\hline Soil & 16 & 18 & 20 & 17 & 17 & 20 \\
\hline
\end{tabular}

GLOBAL WARMING... Global warming is a factor of the $\mathrm{CO}_{2}$ level in the atmosphere. This level indirectly shows the Global Warming Threat Scale for Whole Planet. It is not country specific. At the beginning of the game, it is at the 9 mark. After each player's turn, it automatically goes up by 1 point but also reduced by the amount of the $\mathrm{CO}_{2}$ reduction benefits coming from the Investments. If $\mathrm{CO}_{2}$ level goes over the maximum limit of 20 , game finishes and everybody loses. The minimum value $\mathrm{CO}_{2}$ can be at 3 , cannot be reduced anymore.

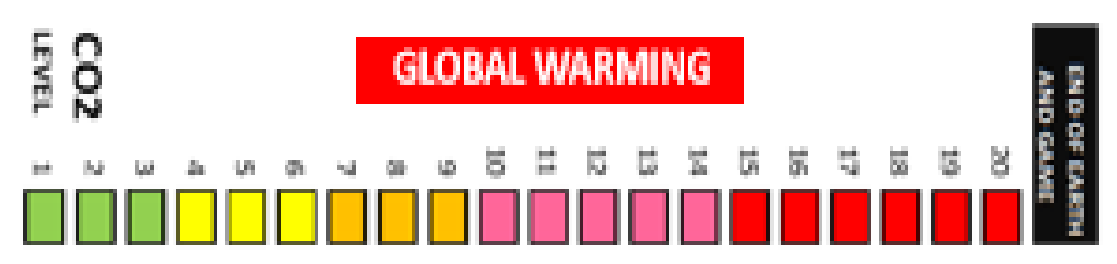


MONEY... Each country starts the game with $w 50$ ecoshin. After each player completes his/her turn, player collects income from all the investments acquired prior to that turn.

Also, each time a player passes the START point, he collects $w 20$ ecoshin.

THE PLAY... Each player in turn throws the dice. The player with the highest total starts the play.

Place your token on the corner marked "START" throw the dice and move your token in the direction of the arrow the number of spaces indicated by the dice. After you have completed your play, the turn passes to the left. The tokens remain on the spaces occupied and proceed from that point on the player's next turn. Two or more tokens may rest on the same space at the same time. According to the space your token reaches, you may be entitled to buy the investment - or draw a Disaster card, etc.

Each time a player's token lands on or passes over START, whether by throwing the dice or drawing a card, the President pays him/her a $w 20$. The $ש 20$ is paid only once each time around the board.

BUYING INVESTMENT... Whenever you land on an unowned investment you may buy that investment from the Union at its printed price and place it face up in front of you. If you do not wish to buy the property, and if the property belongs to Union then the President can sell it at auction to the highest bidder. The buyer pays the Union the amount of the bid in cash and receives that investment. When a player owns an investment, he/she will reduce the pollution level of his /her country as written on the investment card and gives the exact amount of bead to the Union back.

Any player, including the one who declined the option to buy it at the printed price, may bid. Bidding may start at any price. When you land on property owned by another player, the owner might sell the investment to any price he or she decides. If the owner does not want to sell it the player or union cannot force him to do or they cannot bid.

After each player turn both Global Warming and his/her countries pollution levels of air, water, soil increase by one.

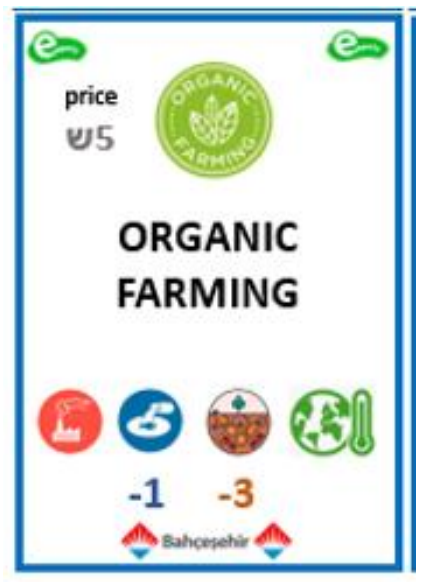

For example, when a player invests "organic farming", his/ her country's water pollution decreases by 1 and soil pollution is decreases by 3 , and this player pays 5ecoshin to the Union. 
But since we still live on this country, and every investment or action has an effect the pollution, air water soil pollution numbers increase by one. So for this sample after the turn, this players air pollution increases by 1 , water remains same, and soil pollution reduces by 2 .

When a player does not prefer to do investment should think about these automatic increases on his/her country's pollution.

Each investment card has its own benefit depend on the type of the investment. Their cost and benefits on reducing pollution are all different and based on scientific approach. Some samples are given below.
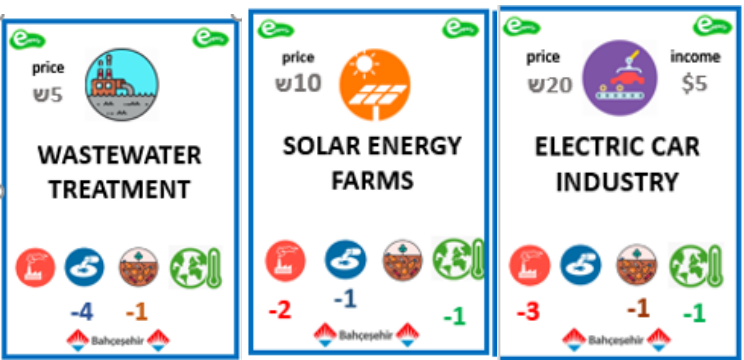

The object of the game is to become the first country to achieve zero pollution level in 3 areas: AIR, WATER, EARTH. When a player has zero pollution at his /her country the game ends, but there is no winner, that player is the first country who has achieved his/her goals first, other players just need more time or money to achieve. Just like real world

$\mathrm{CO}_{2}$ Level which causes Global warming, is a common pollution parameter that applies to all players. If Global warming goes over the maximum limit, everybody loses.
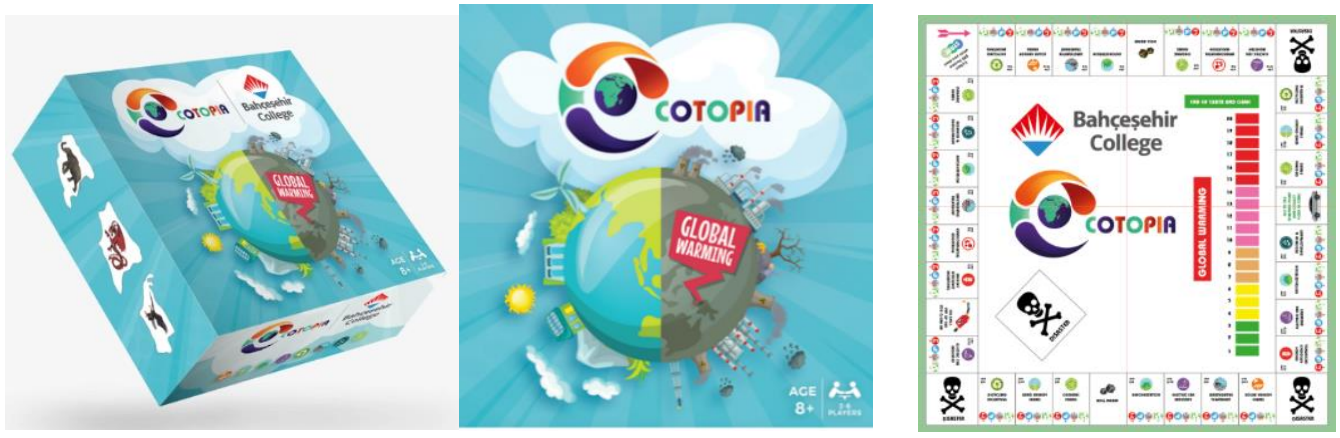

\section{Conclusion}

The main idea of the curriculum is increasing Global Awareness and teaching Sustainable Development Goals (SDG) of UN.

The strategic game Ecotopia is in class tool of the curriculum that focuses on SDG numbers $2,3,4,6,7,13,14,15,17$ by making right investments on the player's country.

As I mentioned before, the object of the game is to become the first country to achieve zero pollution level in 3 areas: AIR, WATER, EARTH. When a player has zero pollution at his /her country the game ends, but there is no winner, that player is the first country who has 


\section{achieved his/her goals first, other players just need more time or money to achieve. Just like real world.}

Since there is no winner, the balance between collaboration and competition has been created. During the game each country trying to reduce his/her pollution. The player can do the following investments: electric car, reforestation, wind energy, solar energy farms, recycling incentives, organic farming, wastewater treatment, energy efficiency incentives, research and development and environmental education.

The players can do only nature friendly investments, for example there is no fuel energy investment in the game so the game focuses on giving a perspective of solution to the pollution. The other important rule about game is making students to understand the importance of making investment, the pollution levels are increasing automatically after each player's turn, if there is no investment, there is zero chance to reach goal.

The other part that I would like to explain about the game is automatic increase of pollution levels. Students should understand that every investment has benefit and advantage on decreasing pollution but meanwhile an effect on pollution. Mean that you can convert all fuel cars to electric cars, but still there is pollution. Electric cars are reducing pollution but not making it zero. So, after a player plays his/her turn, each pollution parameter of that player goes up 1 point. This feature of game is also important about encouraging the students to do investment as I explained above.

Meanwhile all players must be careful about $\mathrm{CO}_{2}$ Level which causes Global warming. This is a common pollution parameter that applies to all players. If Global warming goes over the maximum limit, everybody loses. The Global Warming can be minimum 3 is the other important message that I would like to give students. Warming can be min amount but never be zero.

\section{References}

[1] Seemiller Corey, and Grace meghan,Generation Z Goes to College,2016

[2] -Rieckmann,Marco Education for Sustainable Development Goals: learning objectives, UNESCO Publishing, 2017

[3] -Sauve, Lucie, Environmental Education and Sustainable Development: A Further Appraisal, 1996

[4] Dale, Ann and Newman, Lenore, Sustainable Development, Education and Literacy,

[5] International Journal of Sustainability in Higher Education, 2005

[6] -Glasser, Rae, and Green, Catch: A New, SDG-Aligned Learning for Transformative Change, 2018

[7] --Taysum, alison, Education Policy as a Roadmap for Achieving the Sustainable Development Goals, 2020

[8] -https://www.un.org/

[9] -https://unitar.org/about/offices-training-centres-around-world/cifal-istanbul

[10]--https://unitar.org/courses-learning-events

[11]--https://en.wikipedia.org/wiki/Generation Z

[12]--https://www.kasasa.com/articles/generations/gen-x-gen-y-gen-z

[13]-https://www.iberdrola.com/talent/generation-x-y-z

[14]-https://www.careerplanner.com/Career-Articles/Generations.cfm 